\title{
Composição Florística de Plantas Daninhas em Agrossistemas de CUPUAÇUZEIRO (Theobroma grandiflorum) E PUPUNHEIRA (Bactris gasipaes) ${ }^{1}$
}

\author{
Floristic Composition of Weeds in Agrosystems of Cupuaçu (Theobroma grandiflorum) and \\ Peach Palm (Bactris gasipaes)
}

SOUZA, L.S.A. ${ }^{2}$, SILVA, J.F. ${ }^{3}$ e SOUZA, M.D.B. ${ }^{4}$

\begin{abstract}
RESUMO - A interferência das plantas daninhas nos sistemas agroflorestais varia com a espécie e a densidade de infestação da planta daninha. Este trabalho foi realizado na Fazenda Experimental da Universidade Federal do Amazonas, em monocultivo de cupuaçuzeiro e pupunheira e em sistema agroflorestal (SAF) com estas duas espécies. Havia seis espécies de monocotiledôneas e 15 de dicotiledôneas, e as cinco famílias com maior número de espécies, em ordem decrescente, foram Poaceae, Euphorbiaceae, Fabaceae, Cyperaceae e Verbenaceae. As espécies Desmodium incanun, Cyperus rotundus, Clidemia sp. e Spermacoce verticillata ocorreram nos três cultivos. O maior coeficiente de similaridade de plantas daninhas ocorreu entre os cultivos de cupuaçuzeiro e pupunheira $(54,5 \%)$ e o menor entre o sistema agroflorestal e a pupunha (32,0\%). Quanto à freqüência, Stachytarpheta cayennensis apresentou 33\% de freqüência na área de SAF; Eclipta alba, 44\% de freqüência na área de cultivo de cupuaçuzeiro e na área de cultivo de pupunheira; e D. incanun, C. rotundus e Clidemia sp. apresentaram $44 \%$ de freqüência.
\end{abstract}

Palavras-chave: freqüência, abundância, similaridade, agrofloresta, invasoras.

ABSTRACT - The interference of weeds in agro-forestry systems production factors varies according to species and infestation density. This assay was conducted at the Federal University of Amazonas Experimental Farm, using separate cupuaçu and peach palm plantations and an agro-forestry system (AFS) of both species. Six monocotyledonous and fifteen dicotyledonous species were identified. The major five families with the most number of species were Poaceae, Euphorbiaceae, Fabaceae, Cyperaceae and Verbenaceae, in decreasing order. Desmodium incanun, Cyperus rotundus, Clidemia $s p$. and Spermacoce verticillata were found in the tree cropping systems. The highest weed similarity coefficient was found between the cupuaçu and peach palm plantations (54.50\%) and the lowest between the AFS and peach palm plantation (32.00\%). Starchytapheta cayennensis frequency was 33\% in the AFS area; 44\% for Eclipta alba in the cupuaçu plantation; and $44 \%$ in the peach palm area for $D$. incanun, C. rotundus and Clidemia sp.

Key words: frequency, abundance, similarity, agroforestry, weeds.

\section{INTRODUÇÃO}

Os sistemas agroflorestais ou monocultivos desenvolvidos nos trópicos, freqüentemente, têm apresentado sérios problemas de estabelecimento na fase inicial do plantio e de baixa produtividade, causados pela interferência das plantas daninhas. Nesta região, a grande diversidade, a freqüência e a abundância de plantas, além de pouco estudadas, são

Recebido para publicação em 29.7.2002 e na forma revisada em 11.8.2003.

2 Professora Substituta, Universidade Federal do Amazonas - UFAM, Av. General Rodrigo Octávio Jordão Ramos, 3000, Campus Universitário, 69077-000 Manaus-AM, <saslu@aol.com>; ${ }^{3}$ Professor Adjunto, Dr., UFAM; ${ }^{4}$ Eng.-Agr., M.S., UFAM. 
fatores que dificultam o cultivo vegetal. Nos monocultivos, até o estabelecimento da cultura, ficam espaços e recursos a serem explorados, facilitando a ocupação pelas plantas daninhas, o que não ocorre nos sistemas agroflorestais, onde a área é intensamente ocupada por arranjos de espécies cultivadas que exercem maior pressão de controle sobre as plantas daninhas (Sousa, 1995).

Nos sistemas agroflorestais, os componentes produtivos são alocados para serem eficazes e sustentáveis, de modo a usarem com máxima eficácia os fatores de produção com menor competição entre si. Entretanto, o aparecimento de plantas daninhas pode comprometer o equilibrio dos fatores de produção, por competir com estes para o seu crescimento. Portanto, o estudo de parâmetros populacionais como freqüências absoluta e relativa, abundância e coeficiente de similaridade são importantes para o manejo das plantas daninhas.

Este trabalho teve por objetivo estudar a composição florística das espécies de plantas daninhas que ocorrem nos cultivos de cupuaçuzeiro e pupunheira em monocultura e como componentes de sistema agroflorestal.

\section{MATERIAL E MÉTODOS}

O levantamento das plantas daninhas foi realizado na Fazenda Experimental da Universidade do Amazonas, localizada no km 39 da BR-174, durante o mês de agosto de 2000, em três áreas de cultivo: uma com cupuaçuzeiro de 14 anos de idade, com plantas espaçadas $6 \mathrm{~m}$ entre si; outra de pupunheira da mesma idade e espaçamento; e uma terceira área, plantada em sistema agroflorestal (SAF) com estas duas espécies e cinco anos de idade, cujo espaçamento da pupunheira foi de $3 \times 3 \mathrm{~m}$, e o do cupuaçuzeiro, de $6 \times 6 \mathrm{~m}$.

A precipitação anual média foi de $2.497 \mathrm{~mm}$, com umidade relativa do ar de $85,00 \%$, temperatura média do ar de $26{ }^{\circ} \mathrm{C}$ e $50 \mathrm{~m}$ de altitude.

A amostragem das plantas daninhas foi feita em cada área de estudo, com um retângulo de madeira de $0,50 \mathrm{~m}^{2}$ de área atirado ao acaso, nove vezes em cada área. As plantas daninhas foram cortadas rente ao solo, sendo em seguida identificadas as famílias, os gêneros e as espécies, por comparação na literatura (Lorenzi, 1994; Kissmann \& Groth, 1997) ou no herbário da Universidade Federal do Amazonas ou do INPA.

A freqüência absoluta (FA) das espécies de plantas daninhas expressa a porcentagem de parcelas em que cada espécie ocorre, e a freqüência relativa (FR) é a porcentagem de ocorrência de uma espécie em relação à soma das freqüências absolutas de todas as espécies. Para o cálculo destas freqüências utilizaramse as seguintes fórmulas:

$$
\text { F.A. }=(p \div n) \times 100
$$

em que $\mathrm{F} . \mathrm{A}$. = freqüência absoluta; $\mathrm{p}=$ parcelas ocupadas; e $\mathrm{n}=$ número de parcelas por sistema de cultivo.

$$
\text { F. R. }=\left(\text { F.A. } / \sum^{\mathrm{p}}{ }_{\mathrm{i}=1} \quad \text { F.A. }\right) \times 100
$$

em que $F . R .=$ freqüência relativa da espécie em porcentagem; F.A. = freqüência absoluta da espécie em porcentagem; $p=$ número total de espécies amostrais (Greig-Smith, 1983; Brocki, 2001).

A abundância foi avaliada com base na escala de Maltzew, através da qual se fez uma avaliação geral da comunidade em relação à ocorrência das espécies, da seguinte forma: Sol - espécie encontrada em forma de indivíduos solitários, aparecendo eventualmente no meio da cultura (de 11 a 20\%); Sp - espécie em relativa abundância, havendo, porém, dominância da cultura (de 21 a 30\%); Cop - espécie distribuída e, em alguns lugares, prevalecendo sobre a cultura (de 31 a 40\%); e Dom - distribuição maior que $41 \%$ (Carvalho \& Pitelli, 1992).

$O$ cálculo do coeficiente de similaridade seguiu a equação $C S=[2 \mathrm{C} \div(\mathrm{A}+\mathrm{B})] \times 100$, sendo: $\mathrm{A}=$ número de espécies do habitat $\mathrm{A} ; \mathrm{B}$ $=$ número de espécies do habitat $\mathrm{B}$; e $\mathrm{C}=$ número de espécies comuns aos dois habitats (Sorensen, 1980).

\section{RESULTADOS E DISCUSSÕES}

Quanto às classes, sete espécies pertencem às monocotiledôneas e 15 às dicotiledôneas. As famílias e as espécies encontradas foram: Poaceae (quatro espécies), Euphorbiaceae (três 
espécies), Fabaceae (três espécies), Cyperaceae (duas espécies), Verbenaceae (duas espécies) e uma espécie nas demais famílias, totalizando 21 espécies de plantas daninhas, pertencentes a 12 famílias (Tabela
1). O maior número de espécies da família Poaceae confirma os resultados encontrados por Souza et al. (1998) em áreas com e sem cultivos, em Manaus-AM, e por Modesto Júnior $\&$ Mascarenhas (2001) em pastagens no nor-

Tabela 1 - Famílias e espécies de plantas daninhas por sistema de cultivo e respectivas freqüências absolutas e relativas e abundâncias. Manaus-AM

\begin{tabular}{|c|c|c|c|c|c|c|c|c|c|}
\hline \multirow[b]{2}{*}{ Família/Espécie } & \multicolumn{3}{|c|}{ SAF } & \multicolumn{3}{|c|}{ Cupuaçuzeiro } & \multicolumn{3}{|c|}{ Pupunheira } \\
\hline & $\begin{array}{l}\text { F.A. } \\
(\%)\end{array}$ & $\begin{array}{l}\text { F.R. } \\
(\%)\end{array}$ & Abun & $\begin{array}{l}\text { F.A. } \\
(\%)\end{array}$ & $\begin{array}{l}\text { F.R. } \\
(\%)\end{array}$ & Abun & $\begin{array}{l}\text { F.A. } \\
(\%)\end{array}$ & $\begin{array}{l}\text { F.R. } \\
(\%)\end{array}$ & Abun \\
\hline \multicolumn{10}{|l|}{ Poaceae } \\
\hline Brachiaria mutica (Forsk.) Stapf. & - & - & - & 11 & 2,61 & Sol & - & - & - \\
\hline Homolepis aturensis (H.B.K.) Chase & 67 & 20,9 & Dom & - & - & - & - & - & - \\
\hline Panicum laxum $\mathrm{Sw}$. & - & - & - & 78 & 18,48 & Dom & 67 & 15,51 & Dom \\
\hline Paspalum multicaule Poir. & 11 & 3,43 & Sol & 11 & 2,61 & Sol & - & - & - \\
\hline \multicolumn{10}{|l|}{ Euphorbiaceae } \\
\hline Croton miquelensis Ferg. & 11 & 3,43 & Sol & - & - & - & - & - & - \\
\hline Euphorbia heterophylla L. & - & - & - & - & - & - & 22 & 5,09 & $S p$ \\
\hline Phyllanthus niruri L. & 22 & 6,85 & $\mathrm{Sp}$ & - & - & - & - & - & - \\
\hline \multicolumn{10}{|l|}{ Fabaceae } \\
\hline Desmodium incanun DC. & 78 & 24,30 & Dom & 67 & 15,88 & Dom & 44 & 10,19 & Dom \\
\hline Mimosa pudica L. & 11 & 3,43 & Sol & - & - & - & - & - & - \\
\hline Pueraria phaseoloides (Roxb.) Benth. & - & - & - & - & - & - & 11 & 2,55 & Sol \\
\hline \multicolumn{10}{|l|}{ Cyperaceae } \\
\hline Cyperus rotundus $\mathrm{L}$. & 11 & $\begin{array}{l}3,43 \\
3,43\end{array}$ & Sol & 22 & 5,21 & $\mathrm{Sp}$ & 44 & 10,19 & Dom \\
\hline Rynchospora nervosa ssp. ciliata & - & - & - & 67 & 15,88 & Dom & 100 & 23,15 & Dom \\
\hline \multicolumn{10}{|l|}{ Verbenaceae } \\
\hline Lantana camara $\mathrm{L}$. & 11 & 3,43 & Sol & - & - & - & 11 & 2,55 & Sol \\
\hline Stachytarpheta cayennensis Schauer & 33 & 10,28 & Cop & - & - & - & - & - & - \\
\hline \multicolumn{10}{|l|}{ Asteraceae } \\
\hline Eclipta alba Hassk. & - & - & - & 44 & 10,43 & Dom & - & - & - \\
\hline Convolvulaceae & - & - & & & & & & . & \\
\hline Ipomoea sp. & 22 & 6,85 & $\mathrm{Sp}$ & - & - & - & - & - & - \\
\hline \multicolumn{10}{|l|}{ Clusiaceae } \\
\hline Vismia guianensis Choisy & - & - & - & - & - & - & 11 & 2,55 & Sol \\
\hline \multicolumn{10}{|l|}{ Melastomataceae } \\
\hline Clidemia sp. & 22 & 6,85 & $\mathrm{Sp}$ & 22 & 5,21 & $\mathrm{Sp}$ & 44 & 10,19 & Dom \\
\hline \multicolumn{10}{|l|}{ Arecaceae } \\
\hline Astrocaryum aculeatum G. Meyer & - & - & - & 11 & 2,61 & Sol & - & - & - \\
\hline \multicolumn{10}{|l|}{ Rubiaceae } \\
\hline Spermacoce verticillata (L.) G.F.W. Meyer & 11 & 3,43 & Sol & 89 & 21,09 & Dom & 78 & 18,06 & Dom \\
\hline \multicolumn{10}{|l|}{ Turneraceae } \\
\hline Turnera ulmifolia $\mathrm{L}$. & 11 & 3,43 & Sol & - & - & - & - & - & - \\
\hline
\end{tabular}

Sol = espécie em forma de indivíduos solitários, eventualmente na cultura (11 a 20\%); Sp = espécie em relativa abundância, havendo, porém, dominância da cultura (21 a 30\%); Cop = espécie distribuída e, em alguns lugares, prevalecendo sobre a cultura (31 a 40\%); Dom = espécie encontrada dominando sobre a cultura (acima de 40\%); e SAF- sistema agroflorestal. 
deste paraense.

Quanto ao hábito de crescimento, Lantana camara, Astrocaryum aculeatum, S. verticillata e Vismia guianensis são lenhosas; Eclipta alba e Clidemia sp., semilenhosas; Mimosa pudica, semi-herbácea; e todas as demais espécies são de hábito de crescimento herbáceo (Tabela 2).

Em relação ao ciclo de vida, $C$. rotundus, $D$. incanun, M. pudica, V. guianensis, L. camara, A. aculeatum, Rynchospora nervosa, Stachytarpheta cayennensis, Brachiaria mutica, Turnera ulmifolia, Pueraria phaseoloides e Homolepis aturensis são perenes; Euphorbia heterophylla, Phyllantus niruri, Panicum laxum e Croton miquelensis são anuais; e S. verticillata, E. alba e Ipomoea sp. podem ser perenes ou anuais, dependendo da espécie e das condições do ambiente (Tabela 2).

As espécies amostradas apresentam reprodução sexuada e assexuada, nas seguintes formas: sementes exclusivamente; sementes e rizomas; sementes, brotações de raízes e tubérculos; e sementes, frutos e estolões (Tabela 2).

$\mathrm{Na}$ área de $\mathrm{SAF}$, as espécies B. mutica, P. laxum, E. heterophylla, P. phaseoloides, $R$. ciliata, E. alba, V. guianensis e A. aculeatum não ocorreram nas amostras; as espécies menos freqüentes foram P. multicaule, C. miquelensis, M. pudica, C. rotundus, L. camara, S. verticillata, T. ulmifolia, com $11,00 \%$ de freqüência cada e classificadas como solitárias; $P$. niruri, Ipomoea sp. e Clidemia sp. apresentaram $22,00 \%$ de freqüência, sendo classificadas como espécies relativamente abundantes; e a espécie $S$. cayennensis apresentou $33,00 \%$ de freqüência, sendo classificada como distribuída em alguns lugares, prevalecendo sobre a cultura (Tabela 1).

Na área de cultivo de cupuaçuzeiro, as espécies $H$. aturensis, C. miquelensis, E. heterophylla, P. niruri, M. pudica, $P$. phaseoloides, L. camara, S. cayennensis, Ipomoea sp., V. guianensis e T. ulmifolia não ocorreram nas amostras; $B$. mutica, $P$. multicaule e A. aculeatum apresentaram $11,00 \%$ de freqüência e foram classificadas como solitárias; C. rotundus e Clidemia sp. apresentaram $22,00 \%$ de freqüência, sendo classificadas como relativamente abundantes; e E. alba apre- sentou $44,00 \%$ de freqüência, sendo classificada como espécie dominante (Tabela 1).

$\mathrm{Na}$ área de cultivo com pupunheira, as espécies $B$. mutica, $H$. aturensis, $P$. multicaule, C. miquelensis, P. niruri, M. pudica, S. cayennensis, E. alba, Ipomoea sp., A. aculeatum e T. ulmifolia não ocorreram nas amostras; P. phaseoloides, L. camara e $V$. guianensis apresentaram $11,00 \%$ de freqüência e foram classificadas como solitárias; E. heterophylla apresentou 22,00\% de freqüência, sendo classificada como relativamente abundante; e $D$. incanun, $C$. rotundus e Clidemia sp. apresentaram $44,00 \%$ de freqüência, sendo classificadas como espécies dominantes (Tabela 1).

Ao contrário de $H$. aturensis, $P$. laxum foi a espécie dominante, com $78,00 \%$ e $67,00 \%$ de freqüência nos cultivos de cupuaçuzeiro e pupunheira e ausente no SAF (Tabela 1). A alta freqüência desta espécie nos monocultivos pode ser devido ao fato de a incidência solar ser alta, apesar de estes monocultivos terem 14 anos de idade e as plantas do SAF, 5 anos. Ainda na familia Poaceae, $P$. multicaule ocorre como indivíduo solitário, tanto no SAF quanto no cupuaçuzeiro, e ausente na cultura da pupunheira.

As espécies de Euphorbiaceae ocorrem com relativa abundância, exceto C. miquelensis, que aparece em forma de individuo solitário.

A dominância de $D$. incanun nos três ambientes de cultivo, com $78,67 \%$ e $44,00 \%$ de freqüência no SAF - cupuaçuzeiro e pupunheira, respectivamente - mostra a plasticidade desta espécie de crescer em ambientes com diferentes niveis de luz solar (Tabela 1). Já $M$. pudica e $P$. phaseoloides ocorrem em ambientes com menor e maior incidência de luz, respectivamente, e como indivíduos solitários.

A abundância e a freqüência de $C$. rotundus aumentaram com a luz incidente nos três sistemas de cultivo (Tabela 1 ). O fato de ser uma planta $\mathrm{C}_{4}$, pode explicar a sua dominância no plantio de pupunheira; neste monocultivo há maior incidência solar, por causa do espaçamento usado no plantio e da arquitetura da planta (Carvalho \& Torres, 1994).

Quanto à abundância das espécies dentro dos sistemas de cultivo, verificou-se que no SAF ocorreu dominância de apenas duas 
Tabela 2 - Família, nome científico, nome comum, ciclo de vida, hábito de crescimento, consistência do caule e tipo de reprodução das plantas daninhas amostradas nas três áreas

\begin{tabular}{|c|c|c|c|c|}
\hline Família/Espécie & Nomes vulgares & Ciclo de vida & $\begin{array}{l}\text { Hábito de crescimento/ } \\
\text { consistência do caule }\end{array}$ & Tipo de reprodução \\
\hline \multicolumn{5}{|l|}{ Asteraceae } \\
\hline Eclipta alba Hassk. & $\begin{array}{l}\text { Erva-de-botão, agrião-do- } \\
\text { brejo, cravo-bravo }\end{array}$ & Anual ou perene & $\begin{array}{l}\text { Ereto, subereto ou } \\
\text { prostrado/sublenhoso }\end{array}$ & Sementes \\
\hline \multicolumn{5}{|l|}{ Convolvulaceae } \\
\hline Ipomoea sp. & Corda-de-viola, campainha & $\begin{array}{l}\text { Perene ou anual, } \\
\text { variando com a } \\
\text { espécie }\end{array}$ & $\begin{array}{l}\text { Escandente ou } \\
\text { reptante/Herbáceo }\end{array}$ & Sementes \\
\hline \multicolumn{5}{|l|}{ Cyperaceae } \\
\hline Cyperus rotundus $\mathrm{L}$. & $\begin{array}{l}\text { Tiririca, tiririca-vermelha, } \\
\text { três-quinas }\end{array}$ & Perene & Cespitoso/Herbáceo & $\begin{array}{l}\text { Tubérculos e } \\
\text { sementes }\end{array}$ \\
\hline Rynchospora nervosa ssp. Ciliata & $\begin{array}{l}\text { Capim-estrela, estrelinha, } \\
\text { tiririca-branca }\end{array}$ & Perene & Cespitosa/Herbácea & Sementes \\
\hline \multicolumn{5}{|l|}{ Euphorbiaceae } \\
\hline Croton miquelensis Ferg. & Gervão & Anual & $\begin{array}{c}\text { Rastejante, } \\
\text { ascendente/Herbáceo }\end{array}$ & Sementes \\
\hline Euphorbia heterophylla L. & Leiteira, flor-de-poeta & Anual & Ereto/Herbáceo & Sementes \\
\hline Phyllanthus niruri $\mathrm{L}$. & $\begin{array}{l}\text { Quebra-pedra, arranca- } \\
\text { pedras, erva-pombinha }\end{array}$ & Anual & Ereto/Herbáceo & Sementes \\
\hline \multicolumn{5}{|l|}{ Fabaceae } \\
\hline Desmodium incanun DC. & $\begin{array}{l}\text { Carrapicho beiço-de-boi, } \\
\text { pega-pega }\end{array}$ & Perene & $\begin{array}{l}\text { Prostrado, ascendente ou } \\
\text { subereto/Herbáceo }\end{array}$ & Sementes \\
\hline Mimosa pudica $\mathrm{L}$. & $\begin{array}{l}\text { Dormideira, sensitiva, } \\
\text { malícia, não-me-toques }\end{array}$ & Perene & Prostrado/Semi-herbáceo & Sementes \\
\hline $\begin{array}{l}\text { Pueraria phaseoloides (Roxb.) } \\
\text { Benth. }\end{array}$ & Puerária & Perene & Trepadeira / Herbácea & Sementes \\
\hline \multicolumn{5}{|l|}{ Clusiaceae } \\
\hline Vismia guianensis (Aublet) Choisy & Lacre & Perene & Arbóreo/Lenhoso & $\begin{array}{c}\text { Sementes, brotações } \\
\text { de raízes }\end{array}$ \\
\hline \multicolumn{5}{|l|}{ Melastomataceae } \\
\hline Clidemia sp. & Pixirica, folha-de-fogo & Perene & Subarbustivo/Sublenhoso & Sementes \\
\hline \multicolumn{5}{|l|}{ Arecaceae } \\
\hline Astrocaryum aculeatum G. Meyer & tucumã & Perene & Ereto/Lenhoso & Sementes \\
\hline \multicolumn{5}{|l|}{ Poaceae } \\
\hline Brachiaria mutica (Forsk.) Stapf. & $\begin{array}{l}\text { Capim-angola, capim-branco, } \\
\text { capim-fino }\end{array}$ & Perene & Cespitoso/Herbáceo & $\begin{array}{l}\text { Estólons, frutos, } \\
\text { sementes }\end{array}$ \\
\hline Homolepis aturensis (H.B.K.) Chase & $\begin{array}{l}\text { Capim-pacuã, capim- } \\
\text { amargoso }\end{array}$ & Perene & Cespitoso/Herbáceo & Sementes, rizomas \\
\hline Panicum laxum $\mathrm{Sw}$. & taboquinha & Anual & Cespitoso/Herbáceo & Sementes, rizomas \\
\hline Paspalum multicaule Poir. & Capim-tari-pucu & Perene & $\begin{array}{c}\text { Prostrado, } \\
\text { ascendente/Herbáceo }\end{array}$ & Sementes, rizomas \\
\hline \multicolumn{5}{|l|}{ Rubiaceae } \\
\hline $\begin{array}{l}\text { Spermacoce verticillata (L.) G.F.W. } \\
\text { Meyer }\end{array}$ & $\begin{array}{l}\text { Poaia-botão, vassourinha-de- } \\
\text { botão, poaia-preta }\end{array}$ & Anual/perene & $\begin{array}{c}\text { Ereto ou } \\
\text { decumbente/Lenhoso }\end{array}$ & Sementes \\
\hline \multicolumn{5}{|l|}{ Turneraceae } \\
\hline Turnera ulmifolia $\mathrm{L}$. & Bom dia & Perene & Ereta/Herbácea & Sementes \\
\hline \multicolumn{5}{|l|}{ Verbenaceae } \\
\hline Lantana camara $\mathrm{L}$. & $\begin{array}{l}\text { Cambará, cambará-branco, } \\
\text { chumbinho }\end{array}$ & Perene & $\begin{array}{l}\text { Subarbustivo, } \\
\text { ereto/Lenhoso }\end{array}$ & Sementes \\
\hline Stachytarpheta cayennensis Schauer & Gervão, gervão-azul & Perene & $\begin{array}{l}\text { Subarbustivo, } \\
\text { ereto/Herbáceo }\end{array}$ & Sementes \\
\hline
\end{tabular}


espécies de plantas daninhas - $H$. aturensis e D. incanun, com $67,00 \%$ e $78,00 \%$, respectivamente, de freqüência.

Quanto à associação entre classes e cultivos, a área de cupuaçuzeiro apresentou o maior número de espécies da classe das monocotiledôneas, com seis espécies, seguida das áreas de SAF e pupunheira, com três espécies cada; quanto às dicotiledôneas, a área de consórcio apresentou 10 espécies, seguida da área de pupunheira, com sete, e da área com cupuaçuzeiro, com quatro (Tabela 3 ).

O coeficiente de similaridade expressa as espécies comuns nas áreas avaliadas. A partir deste coeficiente (Tabela 4), as similaridades das espécies de plantas daninhas entre as áreas foram: cupuaçuzeiro $x$ pupunheira $>\mathrm{SAF}$ $x$ cupuaçuzeiro $>$ SAF $x$ pupunheira. $O$ número de espécies de plantas daninhas foi maior entre a área de monocultivo de pupunheira e a de cupuaçuzeiro; a menor quantidade de espécies de plantas daninhas comuns ocorreu entre o SAF e o cultivo de pupunheira.
O maior coeficiente de similaridade entre os monocultivos de cupuaçuzeiro e pupunheira $(54,50 \%)$ e os menores entre os monocultivos e o SAF $(34,80 \%$ e $32,00 \%)$ podem, em parte, ser explicados pelo maior espaçamento entre plantas dos monocultivos e menor no SAF. Além do espaçamento, o cupuaçuzeiro geralmente apresenta maior crescimento, para todas as características, quando cultivado em SAF que em monocultivo, o que contribui ainda mais para diminuir o nivel de luz no SAF, enquanto no monocultivo deixa mais expostas as plantas e o solo à incidência direta dos raios solares (Gasparotto et al., 1997). Resultados semelhantes de indices de similaridade de plantas daninhas, variando de $26,00 \%$ a $38,00 \%$, em quatro diferentes sistemas agroflorestais, em uma pastagem abandonada, também foram encontrados em trabalho realizado no município de Manaus (Sousa, 1995).

As espécies de plantas daninhas da classe monocotiledônea adaptam-se melhor ao

Tabela 3 - Classes, espécies e número de plantas daninhas por sistema de cultivo. Manaus-AM

\begin{tabular}{|c|c|c|c|c|c|c|}
\hline \multirow{2}{*}{ Classe } & \multicolumn{2}{|l|}{ SAF } & \multicolumn{2}{|l|}{ Cupuaçuzeiro } & \multicolumn{2}{|l|}{ Pupunheira } \\
\hline & Espécie & N.P. & Espécie & N.P. & Espécie & N.P. \\
\hline \multicolumn{7}{|c|}{ Monocotiledôneas } \\
\hline- & Homolepis aturensis & 462 & Homolepis aturensis & 462 & Rynchospora nervosa ssp. ciliata & 313 \\
\hline- & Cyperus rotundus & 3 & Rynchospora nervosa ssp. ciliata & 220 & Panicum laxum & 135 \\
\hline- & Paspalum multicaule & 1 & Brachiaria mutica & 112 & Cyperus rotundus & 37 \\
\hline- & - & - & Cyperus rotundus & 92 & - & - \\
\hline- & - & - & $\begin{array}{l}\text { Paspalum multicaule } \\
\text { Paspan mulcan }\end{array}$ & 9 & - & - \\
\hline- & - & - & Astrocaryum aculeatum & 5 & - & - \\
\hline Subtotal & - & 466 & - & 900 & - & 485 \\
\hline \multicolumn{7}{|l|}{ Dicotiledôneas } \\
\hline- & Desmodium incanum & 355 & Eclipta alba & 149 & Spermacoce verticillata & 114 \\
\hline- & Phyllantus niruri & 6 & Desmodium incanun & 70 & Clidemia sp. & 16 \\
\hline- & Stachytarpheta cayennensis & 4 & Spermacoce verticillata & 68 & Euphorbia heterophylla & 8 \\
\hline- & Ipomoea sp. & 3 & Clidemia sp. & 10 & Desmodium incanum & 7 \\
\hline- & Clidemia sp. & 2 & - & - & Vismia guianensis & 6 \\
\hline- & Mimosa pudica & 2 & - & - & Lantana camara & 1 \\
\hline- & Spermacoce verticillata & 2 & - & - & Pueraria phaseoloides & 1 \\
\hline- & Croton miquelensis & 1 & - & - & - & - \\
\hline- & Lantana camara & 1 & - & - & - & - \\
\hline- & Turnera ulmifolia & 1 & - & - & - & - \\
\hline Subtotal & - & 377 & - & 297 & - & 153 \\
\hline Total & & 843 & & $\begin{array}{l}1.1 \\
97\end{array}$ & & 638 \\
\hline
\end{tabular}

SAF - sistemas agroflorestais; N.P. - número de plantas por área amostrada. 
cupuaçuzeiro, enquanto as espécies da classe dicotiledônea estiveram presentes em maior número na área de SAF, o que demonstra que as plantas monocotiledôneas, predominantemente $\mathrm{C}_{4}$, mais agressivas, beneficiaram-se do maior espaçamento existente entre as plantas de cupuaçu; já as espécies dicotiledôneas, na maioria $\mathrm{C}_{3}$, predominaram na área de SAF que apresentou menor incidência de

Tabela 4 - Coeficiente de similaridade (\%) entre as plantas daninhas nos três sistemas de cultivo. Manaus-AM

\begin{tabular}{|l|c|c|c|}
\hline \multicolumn{1}{|c|}{ Cultivo } & Cupuaçuzeiro & Pupunheira & SAF \\
\hline SAF & 34,8 & 32,0 & - \\
\hline Pupunheira & 54,5 & & - \\
\hline Cupuaçuzeiro & - & - & - \\
\hline
\end{tabular}

radiação solar e, conseqüentemente, menor competição com outras espécies que necessitam deste recurso em maiores proporções.

O maior número de indivíduos ocorrentes na área de cultivo de cupuaçuzeiro se deve à prevalência de espécies monocotiledôneas e ao tipo de contagem - cada perfilho é contado como uma planta; o menor número de indivíduos ocorrentes na área de cultivo de pupunheira pode estar associado à produção de biomassa desta espécie, que propicia maior cobertura do solo, dificultando a emergência de plantas daninhas.

\section{LITERATURA CITADA}

BROCKI, E. Sistemas agroflorestais de cultivo e pousio: etnoconhecimento de agricultores familiares do Lago do Paru (Manacapuru, AM). 2001. 166 f. Tese (Doutorado em Ciências Biológicas) - Instituto Nacional de Pesquisas da Amazônia - Universidade do Amazonas, Manaus, 2001.
CARVAlHO, E. F.; TORRES, L. G. Manejo de las malas hierbas em sistemas agroflorestales de Amazonia. Agroflor Am., v. 3, p. 6-9, 1994.

CARVALHO, S. L.; PITELLI, R. A. Levantamento e análise fitossociológica das principais espécies de plantas daninhas de pastagens da região de Selvíria (MS). Planta Daninha, v. 10, n. 1, p. 25-32, 1992.

GASPAROTTO, L.; ARAÚJO, R. C.; SILVA, S. E. L. Cupuaçuzeiro em sistemas agroflorestais-Programa Shift. In: SEMINÁRIO INTERNACIONAL SOBRE PIMENTA DO REINO E CUPUAÇU, 1997, Belém. Anais... Belém: Embrapa, 1997. p. 103-108.

GREIG-SMITH, P. Quantitative plant ecology. 3.ed. Oxford: Blackwel, 1983. 359 p.

KISSMANN, K. G.; GROTH, D. Plantas infestantes e nocivas. São Paulo: BASF Brasileira. v. 2, 1997. 798 p.

LORENZI, H. Manual de identificação e controle de plantas daninhas: plantio direto e convencional. 4.ed. Nova Odessa: Plantarum, 1994. 299 p.

MODESTO JÚNIOR, M. S.; MASCARENHAS, R. E. B. Levantamento da infestação de plantas daninhas associadas a uma pastagem cultivada de baixa produtividade no nordeste paraense. Planta Daninha, v. 19, n. 1, p. 11-21, 2001.

SORENSEN, T. A method of stablishing groups of equal amplitude in plant society based on similarity of species content. In: ODUM, E. P. Ecologia. México: Interamericana, 1972. $640 \mathrm{p}$.

SOUSA, S. G. A. Dinâmica de invasoras em sistemas agroflorestais implantados em pastagens degradadas na Amazônia Central (Região de Manaus-AM). 1995. $97 \mathrm{f}$. Dissertação (Mestrado em Agronomia) - Escola Superior de Agricultura "Luiz de Queiróz", Piracicaba, 1995.

SOUZA, G. F.; SILVA, J. F.; FIGUEIREDO, A. F. Levantamento de plantas daninhas em áreas com e sem cultivos, em Manaus-AM. R. Univ. Amaz Série Ci. Agr., v. 7, p. 33-43, 1998. 